\title{
O currículo escolar em diálogo com a inclusão da pessoa com deficiência: por uma pedagogia das diferenças
}

\author{
The school curriculum in dialogue with the inclusion of the Disabled \\ persons: for a pedagogy of differences
}

\author{
1 Glhevysson dos Santos Barros guersonbarros@gmail.com \\ 1 Caroline Delfino dos Santos
}

1 Universidade do Grande Rio

\begin{abstract}
Resumo
O objetivo deste estudo consiste em discutir a necessidade da construção de práticas curriculares voltadas para a inclusão de pessoas com deficiência nas salas de aulas, partindo de uma perspectiva crítica. Os movimentos de cunho social que se correlacionam à busca de políticas públicas voltadas para as pessoas com deficiência vêm corroborando para a implementação de legislações que dissertam sobre a inserção do grupo populacional não apenas nos espaços institucionais, mas na sociedade. Dessa forma, os presentes documentos legais imprimem-nos alguns questionamentos: em que medida tais marcos legais vêm impactando o processo de escolarização da pessoa com deficiência, bem como, vêm contribuindo para a construção de novas formas de se conceber sua presença nesse cenário, por parte dos outros membros da comunidade escolar? Como (e se) vem sendo possível a (re)construção de um currículo que dialogue com as diferenças instituídas na sala de aula em razão do processo de inclusão. 0 estudo apoiou-se na pesquisa bibliográfica, intercalando-se à pesquisa de caráter documental, utilizando como principais fontes as legislações que se debruçam sobre a educação da pessoa com deficiência. Os resultados do estudo apontam para importantes avanços no que se refere à instituição de políticas alinhadas à compreensão da necessidade do processo de inclusão. Foi possível concluir que, embora hoje tenhamos importantes marcos na história da inclusão da pessoa com deficiência no espaço escolar, tais grupos ainda se configuram como minorias sociais, sendo necessárias políticas que ajudem na desconstrução social de estereótipos demarcados por processos de cunho histórico-cultural.
\end{abstract}

\author{
Palavras-chave \\ Currículo. Inclusão. Desigualdade.
}

\begin{abstract}
The objective of this study is to discuss the need to construct curricular practices aimed at the inclusion of people with disabilities in classrooms, starting from a critical perspective. Social movements that correlate with the search for public policies directed at people with disabilities have been supporting the implementation of legislation that deals with the insertion of the population group, not only in institutional spaces, but in society. Thus, these legal documents present us some questions: to what extent these legal frameworks have impacted the schooling process of the person with disabilities, as well as have been contributing to the construction of new ways of conceiving their presence in this scenario by part of the other members of the school community? How (and if) is it possible to (re) construct a curriculum that discusses the differences established in the classroom due to the inclusion process? The study was based on bibliographical research, interspersed with documentary research, using as main sources the legislation that deals with the education of the disabled person. The results of the study point to important advances in the implementation of policies aligned with the understanding of the need for the inclusion process. It was possible to conclude that, although today we have important milestones in the history of inclusion of people with disabilities in the school space, these groups still configure themselves as social minorities, requiring policies that help in the social deconstruction of stereotypes demarcated by historical and cultural processes.
\end{abstract}

\section{Keywords}

Curriculum. Inclusion. Inequality.

\section{Como você deve citar?}

BARROS, Glhevysson dos Santos; SANTOS, Caroline Delfino dos. O currículo escolar em diálogo com a inclusão da pessoa com deficiência: por uma pedagogia das diferenças. Cadernos UniFOA, Volta Redonda, n. 42, p.81-90, abril, 2020. 


\section{INTRODUÇÃO}

Neste estudo, apontamos como principal eixo temático a discussão sobre o processo de inclusão de pessoas com deficiência, tendo como recorte a construção do currículo escolar a partir da perspectiva das diferenças, tema relevante a ser desenvolvido no presente momento. Assim, elencamos como objetivo discutir a necessidade da construção de práticas curriculares voltadas para a inclusão de pessoas com deficiência nas salas de aulas, partindo de uma perspectiva crítica.

O texto se estrutura a partir de um histórico sobre escolarização da pessoa com deficiência, considerando a divisão entre escolas especiais e escolas regulares, as propostas de mudanças conceituais e também a obrigatoriedade da inclusão, a partir da Lei de Diretrizes e Base da Educação n 9394/96 (LDB) e das Diretrizes Curriculares Nacionais (DCN). Na segunda seção, abordaremos a necessidade da construção de um currículo adaptado para a inclusão do grupo em questão.

Para o desenvolvimento do presente estudo, apoiamo-nos na análise de documentos legais que manifestam em seus princípios o desejo por uma sociedade mais igualitária, em que as diferentes formas de discriminação social possam não apenas ser combatidas, mas, sobretudo, utilizadas como formas de reflexão sobre as trajetórias históricas da representação social da pessoa com deficiência.

Para referenciar o presente trabalho, ressaltamos estudos apresentados por Hugo Otto Beyer, através de sua obra "Inclusão e Avaliação na escola: de alunos com necessidades educacionais especiais". A inclusão a partir de uma pedagogia das diferenças implica no engajamento político de toda comunidade escolar. 0 envolvimento, interação e embasamento teórico sobre as diferenças oportunizam o deslocamento do olhar sobre a deficiência para o olhar sobre a pessoa com deficiência. E aí concentra-se o debate acerca da inclusão: pensar o indivíduo para além de suas limitações em torno de um dado aspecto (motor, intelectual, visual...)

Por pedagogia das diferenças, compreendemos como uma possibilidade de se pensar a dinâmica presente na escola a partir de um olhar, a princípio, consciente de que nesse espaço encontram-se diferentes identidades, a saber, em meio ao próprio grupo por nós elencados. No universo de pessoas com deficiência, deparamo-nos com identidades, surdas, identidades autistas, identidades com síndrome de down e, por vezes, observamos a identidade da pessoa com deficiência múltipla, por englobar mais de uma deficiência. Optamos por utilizar a terminologia identidades no plural por entender que não se trata de uma dada cultura, mas de várias características que se manifestam e, portanto, se fazem presentes dentro da escola.

Dito isto, não negamos a importância da implementação de políticas que se configurem em adequação à infraestrutura, bem como adaptações que favoreçam uma real acessibilidade, contudo reconhecemos que tais mudanças físicas precisam vir acompanhadas de uma ressignificação do olhar sobre as diferenças, sobre as formas de potencialidade de cada indivíduo, para além dos limites que uma deficiência lhe impõe.

As leituras sobre as diferenças divergem na escola. Dado fenômeno não é aleatório. A escola configura-se como um reprodutor em potencial das práticas experenciadas no meio social, portanto, carregando consigo ranços de uma sociedade segregada e segregadora, além de agir com preconceito e discriminação sobre as ditas minorias sociais, mulheres, homossexuais, idosos, indígenas, negros, pessoas com deficiência, não cristãos, pessoas que socialmente não se enquadram dentro dos padrões hétero, europeu, branco, cristão. Essas diferenças evidenciam um grande desafio, que, além de político, apresentam-se como cultural. 
Segundo Aranha (2001), a sociedade, em diferentes épocas, demonstrou atitudes de discriminação e menosprezo às pessoas com deficiência, isolando-as e limitando-as no que se refere ao exercício de sua cidadania. Nesse contexto, a inclusão supera a construção de dispositivos legais que determinem a matrícula e inserção desse aluno nas salas de aula de ensino regular (BEYER, 2005).

É fundamental que o sistema educacional, em suas diferentes esferas, esteja envolvido com a inclusão das pessoas com deficiência, garantindo atendimento às suas necessidades motoras. De igual maneira, reivindica-se que haja uma preocupação quanto ao processo de escolarização, com especial atenção sobre aspectos relacionados ao desenvolvimento intelectual. Assim, esperamos que os conteúdos curriculares possam ser oferecidos de forma acessível, considerando as formas de aprendizagem do grupo em questão, de maneira a contribuir para o seu desenvolvimento motor, socioafetivo e também cognitivo. Para a elucidação do debate sobre currículo e culturas, buscamos bases teóricas sustentadas por Moreira, Candau, Coll, articulando o debate sobre inclusão às discussões que se referem às diferenças. Inserimos as análises e os documentos legais que se referem à educação da pessoa com deficiência, mais especificamente sobre sua inclusão.

Em linhas gerais, os estudos buscam pensar como o currículo escolar pode ser reconfigurado com vistas à inclusão das pessoas com deficiência, estabelecendo relações mais horizontalizadas e destituídas de práticas de discriminação e capacitismo que perpassam pelas dinâmicas estabelecidas na sociedade. Para além do exposto, esperamos que as análises construídas possam contribuir para a ampliação do debate nas instituições escolares e no meio acadêmico.

\section{APONTAMENTOS EM TORNO DA HISTÓRIA DA EDUCAÇÃO ESPECIAL E SUA EVOLUÇÃO}

Ao longo da história da educação especial, podemos identificar diferentes marcos sociais que não se desvinculam das concepções construídas sobre a pessoa com deficiência, conforme contextos temporais, espaciais e culturais. Ao analisarmos pontos importantes sobre a história da educação brasileira, há de se fazer um maior esforço para buscarmos evidências sobre a presença da pessoa com deficiência. Embora os livros que se debrucem sobre a história da educação não o façam de forma articulada à história da educação da pessoa com deficiência, as pesquisas científicas sobre a temática vêm crescendo em grandes proporções e notoriedade.

Nessa seção, objetivamos apresentar mudanças não apenas de caráter conceitual, mas apontar as trajetórias percorridas na educação com o objetivo de se pensar melhores formas de atendimento à pessoa em outros momentos, vistas como especiais. Assim, por mais distante da atual concepção de inclusão construída hoje, não se pode negar que algumas das ações promovidas em dados momentos representaram importantes marcos em relação à época de sua implementação. A partir desse momento, optamos pelo uso de diferentes nomenclaturas atribuídas ao público em debate, que, por vezes, foram utilizadas.

Embora a Igreja tenha se posicionado contra o extermínio das pessoas especiais, essa optou pelo seu enclausuramento, mantendo-as longe da sociedade em troca de sua herança. Os rumos da história da educação especial explicam o porquê de ainda não sabermos lidar com a inclusão da pessoa com deficiência, sendo essa a pauta das nossas inquietações. Se interessa-nos os caminhos a serem construídos a favor da inclusão, não podemos nos abster do fato de que a exclusão tem história. 
Segundo Beyer (2005), havia uma clara divisão entre as crianças ditas normais e as com deficiência. A primeira estudava em escolas regulares e a segunda em escolas especiais. Não existia uma relação entre ambas e os profissionais qualificados para trabalhar com o público especial eram deslocados para diversas escolas para atendê-las. Mas como era o critério para ser encaminhado as crianças às escolas regulares ou especiais? O discente que tinha algum laudo médico e era diagnosticado com algum motivo, como anamnese e história de vida, ia para essas escolas especiais e os ditos normais eram direcionados paras as escolas regulares.

No entanto, com o passar dos anos, houve uma forte reivindicação social para que fossem abertos espaços onde tais indivíduos saíssem de redutos segregados como as escolas especiais destinadas aos que tinham alguma deficiência, incluindo, então, esses alunos especiais na sociedade, tanto em escolas regulares públicas ou privadas como no mercado de trabalho (BEYER, 2005).

Iniciativas referentes à oferta do ensino público no Brasil às massas podem ser contempladas via Lei 15 de outubro de 1827, que manda criar escolas de primeiras letras em todas as cidades, vilas e lugares mais populosos do Império.

D. Pedro I, por Graça de Deus e unânime aclamação dos povos, Imperador Constitucional e Defensor Perpétuo do Brasil: Fazemos saber a todos os nossos súditos que a Assembléia Geral decretou e nós queremos a lei seguinte:

Art. $1^{\circ} \mathrm{Em}$ todas as cidades, vilas e lugares mais populosos, haverão as escolas de primeiras letras que forem necessárias (BRASIL, 1827).

Embora a ampliação das unidades de ensino seja datada do período Brasil-colônia, Beyer (2005) nos chama a atenção para o fato de as crianças com deficiência não serem incluídas nessas escolas, mesmo em períodos mais contemporâneos, com a promulgação de legislações que obrigam a escolarização a partir de dada idade. Tais crianças são mantidas à margem do sistema educacional por um amplo período de tempo em razão de serem consideradas sem presteza ou indisciplinadas. Elas só conseguiram de fato frequentar o sistema de ensino com o surgimento das escolas especiais.

A concentração de pessoas com deficiência em uma escola específica é alvo de críticas contundentes, como afirma Beyer (2005, p. 15): "o equívoco das escolas especiais consiste na reivindicação do monopólio pedagógico com estes alunos, em que se defende a ideia de que a educação especial é o melhor e o mais apropriado para eles."

A história da educação especial, as diversas formas de se entender a situação de indivíduos com deficiência, as explicações socialmente atribuídas às deficiências, bem como os desmembramentos advindos desses podem ser mais bem entendidos a partir da análise paradigmática que o autor faz.

O primeiro, o paradigma clínico médico, pauta-se sobre a compreensão de que as pessoas com deficiência intelectual não conseguiriam ser formalmente educadas. Assim, algumas categorias de professores e médicos, a despeito de inúmeras críticas, lutavam juntos contra tais formas de determinismo, buscando por meio de estudos e pesquisas as possibilidades de aprendizagem. Nesse paradigma, destacam-se a Pedagogia Terapêutica e a Psiquiatria Aplicada. (BEYER, 2005)

Já o segundo paradigma, o sistêmico, está muito atrelado ao primeiro, contudo, voltado para o sistema escolar. Destacam-se dois aspectos importantes nesse paradigma: respeito à atitude a ser tomada e a representação social sobre os alunos especiais. Já o terceiro, a ênfase é maior sobre a questão social. O quarto e último paradigma, pauta-se sobre a crítica Materialista (Marx), que tem uma visão ampliada contrapondo ao modelo clínico, classificando a deficiência como resultado socioeconômico (BEYER, 2005). 
Diante de um passado preconceituoso, excluso para esse grupo, a proposta de inclusão, segundo Beyer (2005), vem sendo tecida desde 1960. Os períodos pós-guerra dão notoriedade aos mutilados sobreviventes, chamando-nos a atenção para as novas demandas trazidas. Já na década de 90, há uma ênfase maior quanto à educação inclusiva, ganhando força com a LDB/1996 e os DCNs de Educação Especial, em 2001. No entanto, uma crítica construída por Beyer (2005) mostra-se relevante, pois

inicialmente, julgamos que uma adequada preparação do professor para as experiências de integração/inclusão é condição básica. Não há como propor uma educação inclusiva, onde "literalmente se jogue, crianças com necessidades especiais nas salas de aula regulares, quando o professor não tem uma formação que lhe possibilite lidar com tais alunos (BEYER, 2005, p.56).

Segundo o autor, por vezes, os profissionais que estão em sala de aula não possuem uma qualificação adequada para trabalhar com esse público, devido a possíveis déficits de formação ou outros aspectos não negados. A formação universitária não deve ser responsabilizada de forma exclusiva. Ressalta-se que, apesar de a Língua Brasileira de Sinais (LIBRAS) ser oferecida em alguns cursos superiores, o profissional, quando formado, não consegue ter amplo domínio sobre ela, assim como pode ocorrer com o ensino do Braile ou outros conhecimentos específicos pertinentes à educação especial. Em decorrência do exposto, por vezes, faz-se necessário o auxílio de outro profissional em sala capaz de promover a mediação entre o professor e o aluno com deficiência. A exemplo, citamos o intérprete de libras, profissão reconhecida no ano de 2010 (BRASIL, 2010). Por meio desse profissional, os alunos surdos podem não apenas aprender sua língua, como experenciar sua cultura para se comunicar com outras pessoas. A oficialização da Língua Brasileira de Sinais (LIBRAS) ganhou forças por meio da lei 10.436, de abril de 2002.

O processo de ensino para os indivíduos com deficiência, pressupõe uma simultaneidade de decisões ao longo da metodologia de ensino, tais como: as adaptações curriculares, os sistemas de comunicação e tipo de escolarização (COLL et al., 2004)

Ainda nos utilizando, como exemplo, da educação dos surdos, temos, segundo Coll et al. (2004, p. 189), as adaptações no currículo escolar, que são necessárias, pois "a correta utilização de um sistema de comunicação manual na sala de aula é a condição necessária para facilitar o intercâmbio de informação com o aluno surdo e o progresso em suas aprendizagens escolares". Portanto, para facilitar o processo ensino aprendizagem desses alunos, é preciso reconfigurar o currículo a favor de sua comunicação e demais necessidades que se fizerem necessárias.

A avaliação desse intercâmbio de informações no âmbito escolar precisa considerar todos os fatores possíveis que refletem no processo de aprendizagem dos educandos surdos como: a comunicação estabelecida entre o professor e os alunos, além da interação desses discentes surdos com colegas surdos ou ouvintes; Importante considerar o tempo de cada aluno no que se refere a aprendizagem, para que haja possibilidade de adaptação do componente curricular, atentando-se sobremaneira aos aspectos físicos presentes na sala de aula: luminosidade, o lugar em que o aluno senta-se durante as aulas, entre outras coisas (COLL et al., 2004)

Embora movimentos correntes se mostrem favoráveis à inclusão, especialistas que estudam o desenvolvimento dos surdos levantam críticas a esse respeito.

A integração marginaliza a linguagem de sinais, que é necessária para a comunicação das pessoas surdas e para a construção de sua própria identidade; os professores das escolas ouvintes não tem formação suficiente; os alunos surdos tem series dificuldades de comunicação oral e, por isso, a integração social com seus colegas pode não ocorrer, mesmo estando na mesma turma; e os alunos surdos não podem acompanhar as informações transmitidas oralmente, o que leva a aumentar seus problemas de aprendizagem (COLL et al., 2004, p. 190). 
Não por acaso, o debate sobre a inclusão se revela complexo, dada a necessidade de se pensar um currículo de caráter flexível em diálogo com o grupo de pessoas com deficiência.

Uma leitura sobre o Transtorno do Espectro Autista revela que a pessoa diagnosticada com TEA pode apresentar sinais comportamentais de agressividade e/ou impulsividade decorrentes ou não de alterações a estímulos sensoriais. Tais respostas podem ser decorrentes da luminosidade ou som alto, além de questões alimentares. De acordo com Coll et al. (2004), esses traços são frequentes nesse público, mas não há como fazer um diagnóstico somente a partir dos sinais manifestados. Também não é possível afirmar que todas as pessoas com dado transtorno apresentam as mesmas características e reações comportamentais. Assim, o processo de inclusão e adaptação curricular é muito singular, pois varia conforme a percepção do autista e varrições espaciais. 0 contexto ao entorno desse aluno nem sempre se revela favorável ao seu bem-estar e desenvolvimento. Assim, a inclusão desse grupo está submetida a outros fatores de caráter também social.

\begin{abstract}
Os sistemas homogêneos e os modelos pouco individualizados do processo de ensino aprendizagem são incapazes de atender as necessidades das crianças cujo modo de desenvolvimento se afasta mais do "modelo padrão de desenvolvimento humano". Por outro lado, dado a enorme heterogeneidade dos quadros de autismo e TGD, a avaliação específica e concreta de cada caso é que deve indicar as soluções educativas adequadas (COLL et al., 2004, p. 249).
\end{abstract}

Segundo Coll et al. (2004), o autista pode ser classificado segundo a DSM-IV da Associação Americana de Psiquiatria e o CID-10 da Organização Mundial da Saúde. O DSM-IV diferencia os transtornos autistas em síndrome de Kanner, o transtorno de Asperger, transtorno de Rett e o TGD. Já os autistas, podem ter graus leves ou severos dependendo de cada indivíduo. Assim, é importante frisar que não é porque o diagnóstico o considerou como autista que as crianças devem ser tratadas da mesma forma. É preciso definir a orientação educativa para cada caso, ou seja, suas particularidades. Cada criança precisa de atendimento diferenciado, de acordo com o seu desempenho. 0 currículo deve ser adaptado de acordo com a necessidade apresentada pelo aluno.

A partir do próximo tópico, será explicada a importância do currículo escolar adaptado no processo de inclusão dos alunos com deficiência.

\title{
3 EDUCAÇÃO ICLUSIVA: A IMPORTÂNCIA DO CURRÍCULO ADAPTADO
}

Mas, afinal, o que é currículo? Para Moreira e Candau (2007, p.18), o currículo é entendido como "os conteúdos a serem ensinados e aprendidos; as experiências de aprendizagem escolares a serem vividas pelos alunos; os planos pedagógicos elaborados por professores, escolas e sistemas educacionais". Nesse contexto, a participação dos professores no processo de elaboração de currículo escolar é ponto essencial, implicando sobretudo, em comprometimento e dedicação no direcionamento do que, de fato, é importante ser ensinado em sala de aula, tanto para as crianças do ensino regular quanto àquelas que a ele precisam democraticamente ser incluídas. Para Moreira \& Candau (2007),

\footnotetext{
as discussões sobre currículo incorporam, com maior ou menor ênfase, discussões sobre os conhecimentos escolares, sobre procedimentos e as relações sociais que conformam o cenário em que os conhecimentos se ensinam e se aprendem, sobre as transformações que desejamos efetuar nos alunos e alunas, sobre os valores que desejamos inculcar e sobre as identidades que pretendemos construir (MOREIRA; CANDAU, 2007, p.18).
}

Para tais autores, dentro do contexto escolar, temos dois tipos de currículo: o formal e o oculto. 0 primeiro é planejado e elaborado por meio do trabalho em conjunto entre professores, partindo da concepção de que o saber e as experiências escolares advindos de cada docente corroboram para a construção do conhecimento. 0 currículo formal tem ainda como objetivo 
traçar os rumos da escola, as atividades que serão organizadas, visando à oferta do ensino e aquisição de aprendizagens pelos sujeitos sociais. Ressaltamos que, para auxiliar na elaboração do currículo com caráter formal, recorre-se a importantes documentos legais que podem, a despeito de algumas críticas, subsidiar teoricamente as ações docentes. Destacamos as diretrizes curriculares, LDB-Lei de Diretrizes e Bases, além das propostas curriculares elucidadas por cada estado e município. A atenção em torno do currículo justifica-se por esse, por vezes, ser concebido como o "coração da escola o espaço central em que todos atuam o que nos torna, nos diferentes níveis do processo educacional, responsáveis por sua elaboração" (MOREIRA E CANDAU, 2007, p.19).

Assim, trabalhar um currículo voltado para os assuntos como inclusão é possibilitar o debate em torno dos desafios que são enfrentados por essas pessoas em busca da igualdade, as evoluções e possibilidades encontradas até um dado momento (MOREIRA; CANDAU, 2007), envolvendo atores importantíssimos ao processo de reflexão: os professores.

No que se refere ao currículo oculto, inferimos que ele corresponde às ações não tecidas no universo da formalidade, estando implícitos, portanto nas relações cotidianas entre os pares. Referese aos valores impressos na dinâmica, nos rituais, nas experiências não institucionalizadas, mas instituídas no/pelo dia a dia da comunidade escolar. São os gestos, as palavras ditas, mas também as palavras não ditas. 0 currículo oculto se manifesta sobre as formas de organização adotadas nesses espaços que compõem o cenário escolar, podendo demarcar territórios e relações de poder mesmo entre os ditos iguais. Ele estabelece as relações espaciais e de temporalidades não previstas nos documentos oficiais, mas que estão carregadas de sentido e intencionalidade, demarcando posições. E é por meio do currículo oculto que vimos a possibilidade de desenvolver leituras fundamentais sobre a inclusão da pessoa com deficiência. Trata-se, pois, de elementos pertencentes às diferentes culturas, bem como o olhar sobre tais diferenças, que estamos a falar.

Como relatam Moreira e Candau (2007), no que se refere às culturas inerentes aos alunos, não se trata de sobrepor um saber a outro, mas possibilitar, na sala de aula. a desinvibilização de identidades historicamente ocultadas e também silenciadas em razão de preconceitos cultivados em meio à sociedade desigual. Cada grupo identitário ou movimento tem sua cultura, interesses e lutas compartilhadas com o intuito de estabelecer um encurtamento dessas diferenças sociais, tão perpetuado em nosso país.

A inclusão é também uma questão de cunho cultural e não por acaso recorremos aos autores em questão. As pessoas com deficiência tradicionalmente são enxergadas como os que não se enquadram num dado grau de normalidade. Nesse contexto, questionamos o que é ser normal tendo em vista a complexidade do corpo humano e as diversidades que nos constituem.

Moreira e Candau (2007, p. 27) ressaltam que "a palavra cultura implica, portanto, o conjunto de práticas por meio das quais significados são produzidos e compartilhados em grupos". Assim, é papel curricular docente oportunizar meios para que os alunos reflitam sobre a ideia de as diferenças de cunho social fazerem parte da construção cultural de um dado grupo. No que se refere às diferenças que intitulam o indivíduo como pessoa com deficiência física, é importante prover meios para que tais alunos não as enxerguem como limitadores ou artifícios para a perpetuação de práticas discriminatórias e segregadoras.

Moreira e Candau (2007) apontam algumas das expectativas em relação ao papel do currículo na elucidação e trato das diferenças, pois 
cabe destacar, na contextualização e na compreensão do processo de construção das diferenças e desigualdade. Nosso propósito é que os currículos desenvolvidos tornem evidente que elas não são naturais; são, ao contrário, "invenções/construções" históricas de homens e mulheres, sendo, portanto, passíveis de serem desestabilizadas e mesmo transformadas. Ou seja, o existente nem pode ser aceito sem questionamento nem é imutável; constitui-se, sim em estímulo para resistências, para críticas e para a formulação e a promoção de novas situações pedagógicas e novas sociais (MOREIRA; CANDAU, 2007, p. 30).

Consideramos, ainda, alguns artigos na Lei de Diretrizes e Bases (LDB) dedicados à temática da inclusão de pessoas com deficiência nas escolas regulares de ensino, tal como apontado no artigo 58.

Entende-se por educação especial, para os efeitos desta Lei, a modalidade de educação escolar oferecida preferencialmente na rede regular de ensino, para educandos com deficiência, transtornos globais do desenvolvimento e altas habilidades ou superdotação (BRASIL, 1996).

Dessa maneira, a própria lei determina, nos parágrafos primeiro, segundo e terceiro, a ideia de que, quando for necessário, haverá pessoas qualificadas para dar suporte a esse público nas escolas regulares de ensino, assim como citado anteriormente no caso das crianças surdas e autistas. Além disso, a oferta da educação especial começa na educação básica, ou seja, desde a educação infantil.

O currículo escolar também é contemplado na lei, no que se refere ao processo de inclusão, especificamente através do Artigo 59, nos itens I, II, III, IV e V, em que é ressaltada a organização para o atendimento da pessoa com deficiência nas escolas regulares, dentre as quais, as que apresentam transtornos globais do desenvolvimento e ainda as que têm altas habilidades ou superdotação. A lei considera, então, a (re)configuração de dados aspectos:

\begin{abstract}
I - currículos, métodos, técnicas, recursos educativos e organização específicos, para atender às suas necessidades; II - terminalidade específica para aqueles que não puderem atingir o nível exigido para a conclusão do ensino fundamental, em virtude de suas deficiências, e aceleração para concluir em menor tempo o programa escolar para os superdotados; III - professores com especialização adequada em nível médio ou superior, para atendimento especializado, bem como professores do ensino regular capacitados para a integração desses educandos nas classes comuns; IV - educação especial para o trabalho, visando a sua efetiva integração na vida em sociedade, inclusive condições adequadas para os que não revelarem capacidade de inserção no trabalho competitivo, mediante articulação com os órgãos oficiais afins, bem como para aqueles que apresentam uma habilidade superior nas áreas artística, intelectual ou psicomotora; $\mathrm{V}$ - acesso igualitário aos benefícios dos programas sociais suplementares disponíveis para o respectivo nível do ensino regular (BRASIL, 1996).
\end{abstract}

Tal como visto na LDB, há ainda outros documentos que abordam a importância do currículo adaptado no contexto escolar, conforme necessidades apontadas. Para esse fim, elegemos as DCNs que apontam que

as dificuldades de aprendizagem na escola apresentam-se como contínuo, compreendendo desde situações mais simples e/ou transitórias - que podem ser resolvidas espontaneamente no curso do trabalho pedagógico - até situações mais complexas e/ou permanentes - que requerem o uso de recursos ou técnicas especiais para que seja viabilizado o acesso ao currículo por parte do educando. Atender a esse contínuo de dificuldade requer respostas educativas adequadas, que abrangem graduais e progressivas adaptações de acesso ao currículo, bem como adaptações de seus elementos (BRASIL, 2001, p. 58).

Beyer (2005) afirma que o currículo escolar precisa passar por mudanças. É preciso pensar em formulações para atender a educação especial, já que "o princípio da educação inclusiva é não alijar ninguém das condições gerais de progressão escolar" (BEYER, 2005, p. 69).

O autor (2005) destaca que o currículo escolar voltado para alunos com deficiência precisa ter uma estrutura flexível e adaptado de acordo com a necessidade do educando, dando ênfase sobre as formas de aprendizagem. 0 aluno que apresenta graves comprometimentos mentais, a saber a pessoa com deficiência múltipla, não pode ser incluído dentro do currículo da base nacional comum e sim num currículo funcional, como aponta as Diretrizes Curriculares Nacionais (DCNs), para, então, atender às necessidades práticas da vida (BRASIL, 2001). 
No que se refere ao currículo adaptado, os estudos apontam para sua pertinência, assim como para a necessidade de um olhar sobre a formação dos profissionais, preparando-os para lidar com essas pessoas.

\section{CONSIDERAÇÕES FINAIS}

O estudo da história da educação não pode estar desvinculado da história da educação especial no Brasil sob o risco de seguirmos concebendo esta como algo à parte, que interessa apenas aos profissionais desse segmento (em caso de Classes Especiais e Salas de Recursos). A inclusão da pessoa com deficiência não é mais uma possibilidade. É uma realidade nas salas de aula brasileiras e nos impõe a necessidade de estudar metodologias de ensino que melhor contemplem as demandas apresentadas pelo aluno com deficiência, reconfigurando, assim, o currículo escolar conforme demandas apontadas.

Diante do exposto, é preciso pensar também numa reestruturação curricular do ensino superior voltado para os cursos de licenciatura, pois muitos profissionais, ao ingressarem no mercado de trabalho, recebem alunos com algum tipo de deficiência, sem contudo, possuírem a formação necessária para lidar com esse público.

Acreditamos, portanto, que, através do trabalho coletivo voltado para a construção de um currículo adaptado, haja mais possiblidades de se conceber uma educação de fato inclusiva. Soma-se a esse movimento o estudo e busca por conhecimentos científicos, atrelados ao diálogo com a família, que, apesar de passarem por uma fase de negação da deficiência, pode contribuir com importantes dados sobre o cotidiano e experiências dos alunos.

A universalização do ensino e as recentes políticas de inclusão nos desafiam a pensar a escola como um espaço diversificado, múltiplo e heterogêneo. As demandas contemporâneas nos impõem a reflexão sobre novas estratégias de ensino e metodologias outras, para além do que rotineiramente nos habituamos a desenvolver. As reconfigurações da sala de aula e do público atendido nos impõem uma mudança de rota, vide as trajetórias construídas até então ainda se revelarem como excludentes. É nesse sentido que a história se apresenta como fundamental. É preciso saber que bases subsidiaram nossas ações até então, as práticas que fundamentam o atual modelo de inclusão e em que circunstâncias dadas políticas públicas foram implementadas, para que possamos reconfigurar as trajetórias da educação da pessoa com deficiência. 


\section{REFERÊNCIAS}

ARANHA, M. S. Paradigmas da relação da sociedade com as pessoas com deficiência. Revista do Ministério Público do Trabalho, n.21, p.160-173, 2001.

BORTOLINI, A. Diversidade sexual e de gênero na escola: educação, cultura, violência e ética. 1. ed. Rio de Janeiro: Pró-reitoria de extensão/UFRJ, 2008.

BEYER, H. O. Inclusão e avaliação na escola: de alunos com necessidades educacionais especiais. Porto Alegre: Mediação, 2005.

BRASIL. Lei de 15 de outubro de 1827. Disponível em: http://www2.camara.leg.br/legin/fed/lei_sn/18241899/lei-38398-15-outubro-1827-566692-publicacaooriginal-90222-pl.html. Acesso em: 30 jan. 2019.

BRASIL. Ministério de Educação e do Desporto. Lei de Diretrizes e Bases da Educação Nacional. Brasília: MEC, 1996.

BRASIL. Ministério da Educação. Secretaria de Educação Especial. Diretrizes Nacionais para a Educação Especial na educação básica. Brasília: MEC/ SEESP 2001.

BRASIL. Lei $n^{\circ}$ 12.319, de 01 de setembro de 2010. Regulamenta a profissão de Tradutor e Intérprete da Língua Brasileira de Sinais - LIBRAS. Diário Oficial da União, Brasília, DF, 2 set. 2010. Disponível em: <http://www.planalto.gov.br/ccivil_03/_Ato2007-2010/2010/Lei/L12319.htm>. Acesso em: 01 jun. 2016.

BRASIL. Lei n 10.436, 24 de abril de 2002. Dispõe sobre Língua Brasileira de Sinais - Libras e dá outras providências. Diário Oficial da União, Brasília, DF, 25 abr. 2002. Disponível em: <http://www.planalto. gov.br/ccivil_03/leis/2002/110436.htm>. Acesso em: 01 jun. 2016.

COLL, C. et al. Desenvolvimento psicológico e educação: necessidade educativas e aprendizagem escolar. Porto Alegre: Artes Médicas, 2004.

MOREIRA, A. F. B.; CANDAU, V. M. Indagações sobre currículo: currículo, conhecimento e cultura. Brasília; Ministério da Educação, Secretaria de Educação Básica, 2007. 